\title{
COMPUTER SIMULATION OF MICROSEGREGATION OF SULPHUR AND MANGANESE AND FORMATION OF MnS INCLUSIONS WHILE CASTING RAIL STEEL
}

\begin{abstract}
The quality of rail steel is conditioned by its high mechanic qualities, which greatly depend on the presence of undesired nonmetallic inclusions. The paper is devoted to the segregation of components, mainly sulphur, and the formation of manganese sulphide in the process of steel solidification, at the casting rate of 100 and $500 \mathrm{~K} / \mathrm{min}$. Sulphur is a steel component which disadvantageously influences its numerous parameters. The oxide-sulphide and sulphide precipitations cause cracks and lower the strength of the material. This phenomenon was modeled with the use of author's computer program based on Matsumiya interdendritic microsegregation model. The main assumptions of this model and thermodynamic conditions of inclusion formation during casting of steel are discussed in this paper. Two cases were analyzed: in the first one the MnS was assumed to form a pure and constant compound, whereas in the other one the manganese sulfide was precipitated as a component of a liquid oxide solution, and its activity was lower than unity. The final conclusion is that chemical composition of steel is the major parameter deciding about the formation of $\mathrm{MnS}$ inclusions.
\end{abstract}

Keywords: solidification, stal szynowa, MnS precipitates

\section{Introduction}

Materials used for the rails production must meet high requirements regarding the properties of materials, shape and durability. The Rolling Contact Fatigue (RCF) is an important issue in the exploitation of a rail steel. Nonmetallic $\mathrm{Al}_{2} \mathrm{O}_{3}, \mathrm{SiO}_{2}$ and $\mathrm{MnS}$ inclusions which frequently appear in the material have a negative impact on the durability of rail and lower RCF. Big and brittle inclusions containing $\mathrm{Ca}, \mathrm{Al}$, $\mathrm{O}$ and $\mathrm{Si}$ may initiate critical cracking under the surface of the rail head. These precipitations may directly influence the generation of cracks because they are not deformed in line with the matrix. This stems from the stresses on the inclusion and matrix interface. In this case the cracks may propagate causing permanent damaging of the material. Big nonmetallic inclusions, e.g. $\mathrm{Al}_{2} \mathrm{O}_{3}$ and $\mathrm{SiO}_{2}$ are possible initiators of the cracking than their smaller counterparts, e.g. sulphides. The results of experiments conducted by Liu [1] revealed that in the nonmetallic inclusions are not deformed evenly the course of rolling. Pure MnS inclusions are deformed in the direction of rolling. In the case of complex inclusions containing manganese sulphur the deformation considerably differs from that of pure MnS. The manganese sulphide may be surrounded by brittle oxidic phases, it may constitute a plastic cover on oxidic phase in the course of heterogeneous nucleation $[2,3]$. In this case their deformation may result in flattening and elongation of inclusions, and in the presence of brittle phases - cracks may appear. The removal of oxidic inclusions, i.e. refinery products was fully managed by a number of operations of secondary and tertiary metallurgy, though the problem of sulphide formation is mainly associated with the final stage of steel production, i.e. casting.

One of the factors influencing the strength parameters of rail steel is sulphur, i.e. the main component of MnS. Sulphur is commonly considered to be a negative element of steel, except for the situation it is purposefully added to improve its machinability. The phase plot of $\mathrm{Fe}-\mathrm{S}$ reveals the existence of eutectics of melting temperature $988^{\circ} \mathrm{C}$ and sulphur content 31 wt.\%. This eutectics was precipitated on the boundary of grains where the steel solidifies. This makes the steel brittle during rolling [4].

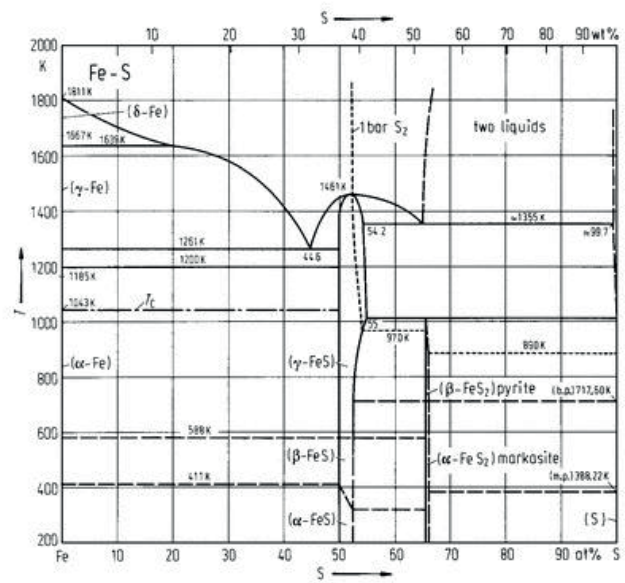

Fig. 1. Phase equilibrium of Fe-S [4]

\footnotetext{
* AGH UST FACULTY OF FOUNDRY ENGINEERING, AL. A. MICKIEWICZA 30, 30-059 KRAKÓW, POLAND

** INSTITUTE OF METALLURGY AND MATERIALS SCIENCE POLISH ACADEMY OF SCIENCE, 25 REYMONTA STR., 30-059 KRAKÓW, POLAND

*** AGH UST FACULTY OF METALS ENGINEERING AND INDUSTRIAL COMPUTER SCIENCE, AL. A. MICKIEWICZA 30, 30-059 KRAKÓW, POLAND

* Corresponding author: dak@agh.edu.pl
} 
Sulphur also acts negatively in steel which works at low temperatures, as it lowers the resistance to mechanical notch in varying load conditions. For this reason steel should not contain more than $0.005 \%$ of sulphur, which is an insurmountable value for materials from which are made constructions, vehicles and pipelines operating in low temperature conditions, as well as materials for transport [1]. Chemically, manganese is closer to sulphur than iron; the $\mathrm{MnS}$ precipitations not only lower the mechanical properties of steel but also cause hydrogen accumulation on the grain interface during welding jobs, bringing about microckacks [2]. It was experimentally concluded that this shortcoming is closely connected with sulphur content in steel [3]. Another unfavorable effect caused by the presence of sulphur is the process of absorption of gaseous bubbles by the solidification front at an early stage of crystallization as a result of gradient of surface tension near the solidification front. This in turn, is connected with the gradient of sulphur content in steel, which will be generated as a consequence of sulphur segregation in the solidification front [3-7]. The paper is devoted to the processes of sulphur and manganese microsegregation in the process of rail steel crystallization. Another issue is modelling of $\mathrm{MnS}$ precipitations in the casting process of rail steel containing $0.016-0.039 \%$ of sulphur.

\section{Microsegregation of components during solidification}

Microsegregation of alloy components can bring about certain undesired features, unless other thermal operations are conducted to make the concentration of steel components more uniform. If controlled, it has a decisive influence on the formation of precipitations and formation of the desired structure. Manganese sulphide precipitations of liquid oxidicsulphidic solution are mainly formed in the process of steel solidification, and the phenomenon is conditioned by the thermodynamic criterion of nonmetallic phase formation and by obtaining suitable concentrations of elements in liquid steel. In the case of rail steel these are mainly sulphur, manganese and oxygen. In the process of steel solidification the steel components are segregated on the solidification front, thanks to which their concentration increases, and on the other hand the distribution and size of the oxidic or sulphidic inclusions is conditioned by the solidification rate.

The formation of the manganese sulphide in liquid steel can be written in the following way [8]:

$$
[\mathrm{Mn}]+[\mathrm{S}]=(\mathrm{MnS})
$$

$\log \mathrm{Q}=-8627 / \mathrm{T}+4.745$

where: $\mathrm{T}$ - temperature $[\mathrm{K}], \mathrm{Q}$ - solubility product.

The formation of manganese sulphide is possible if the following dependence holds true:

$$
\begin{gathered}
Q_{\text {real }}>Q_{\text {equilibrium }} \\
Q_{\text {real }}=\left[\left(C_{M n}\right) \cdot\left(C_{S}\right)\right] \text { real }
\end{gathered}
$$

$Q_{\text {real }}$ means a real value of the $\mathrm{MnS}$ solubility product.
$\mathrm{C}_{\mathrm{Mn}}$ and $\mathrm{C}_{\mathrm{S}}$ denote actual concentrations of components in the liquid solution (expressed in mass percent).

Qequilibrium - denotes equilibrium value of the product, which stems from the condition:

$$
K=\exp \left[-\frac{\Delta G^{0}}{R T}\right]=\frac{a_{M n S}}{[\% M n] \cdot[\% S] \cdot f_{M n} \cdot f_{S}}
$$

where: $\mathrm{K}$ - equilibrium constant of chemical reaction, $\mathrm{T}$ temperature $[\mathrm{K}]$, aMnS - activity of $\mathrm{MnS}, \mathrm{R}$ - gas constant $\left[\mathrm{J} \cdot \mathrm{mol}^{-1} \cdot \mathrm{K}^{-1}\right], \mathrm{f}_{\mathrm{S}}, \mathrm{f}_{\mathrm{Mn}}-$ activity coefficients.

The thermodynamic criterion of precipitations formation refers to the current composition of liquid phase, which undergoes changes changes during steel solidification due to the segregation of components. The analysis of the liquidus and solidus plots of proper bi-component (iron-steel component) system reveals that this component will accumulate in liquid phase, i.e. successive portions of solidifying liquid will be enriched in it. If the crystallization has a dendritic character, then the last portions of the solidifying liquid located between the secondary dendrite arms will have the highest concentration of soluble components. Microsegregation favors formation of inclusions as a result of chemical reactions, mainly oxidic and sulphidic. The quantitative measure of microsegragation of a component is its equilibrium partition coefficient into solid and liquid phases $k_{i}$, defined as:

$$
k_{i}=\frac{C_{S}^{*}}{C_{L}^{*}}
$$

$C_{S}^{*}$ - concentration of a component in the solid phase on the solidification front, $C_{L}^{*}$ - in the liquid phase, $k$ - equilibrium partition coefficient for solid/liquid phase interface.

The effect of enrichment of liquid phase in alloy components is weakened by the concurrent diffusion of components in the forming solid phase, i.e. back diffusion. The concentration of the component in the solid phase on the solidification front is formed by the solidification front movement rate and the diffusion rate in the solid phase. The participation of back diffusion for an individual component ,i" of liquid solution is characterized by the back diffusion parameter $\alpha_{i}$ :

$$
\alpha_{i}=\frac{D_{i} \cdot t_{s}}{l^{2}}
$$

$\alpha_{i}$ - back diffusion parameter, $D_{i}$ - diffusion coefficient of a component in the formed solid phase $\left[\mathrm{m}^{2} \cdot \mathrm{s}^{-1}\right], l$ - movement of solidification front $[\mathrm{m}],], t_{s}-$ time $[\mathrm{s}]$.

Crystallization with the back diffusion was described with some equations. Wołczyński equation was used in this paper [9]:

$$
C_{S}^{*}=k \cdot C_{0} \cdot\left[1+\alpha \cdot k \cdot f_{S}-f_{S}\right]^{\frac{k-1}{1-\alpha \cdot k}}
$$


important role because it determined whether or not inclusions are formed. Two cases are possible here: particular compounds precipitate sequentially $(\mathrm{a}=1)$, or two or more compounds are simultaneously precipitated in a certain interval of temperatures, and which form a liquid compound $(\mathrm{a}<1)$. If the activity of the formed compound is taken into account, the condition in which precipitations are formed has the following form:

$$
\text { Qreal }>\text { Qequilibrium } \cdot a_{A_{a} B_{b}}
$$

The dependance of the solubility product $\mathrm{Q}$ on temperature for manganese sulphide is presented in fig. 2 . The equilibrium value of the solubility product strongly varies with temperature.

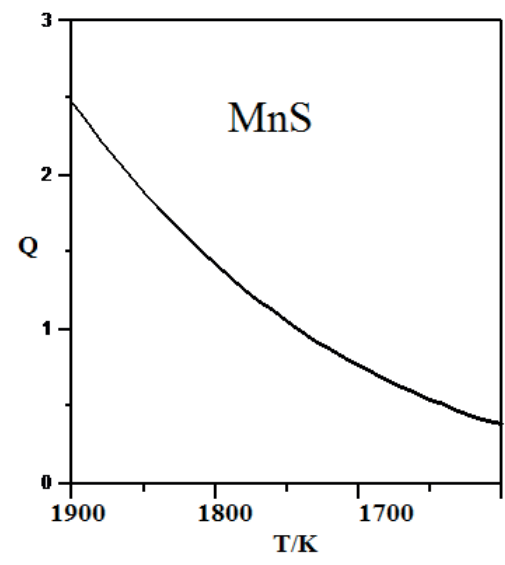

Fig. 2. Course of equilibrium dependence of $\mathrm{MnS}$ solubility vs. temperature

The work makes use of a model based on the concept worked out by Matsumiya et al. [10], which was also employed in other works [8, 11-13]. It accounts for the coupling of microsegregation and inclusions formation, which allows for approaching the real course of this process. If the microsegregation of components were calculated separately (e.g. with equation 7), and on this basis the number of inclusions then in some cases the concentrations in the end parts of the liquid phase would be overrated. This was revealed in the work by Ma and Janke [11]. It was also assumed that the boundary of phases s/l moves following the parabolic law:

$$
\frac{d f_{S}}{d t} \propto \frac{1}{\sqrt{t}}
$$

The back diffusion effect was described by diffusion equation (II Fick's II Law) for each steel component:

$$
\frac{\partial C}{\partial t}=D_{i} \cdot \frac{\partial^{2} C}{\partial x^{2}}
$$

$\mathrm{x}$ - horizontal coordinate: $0 \leq x \leq \lambda / 2$

\section{Results of calculations of microsegregation and MnS precipitations formation}

The process of microsegregation and inclusion formation in rail steel of chemical composition as in Table 2 was simulated. Authors used own computer software based on the worked out model [7,14]. The calculations were performed for two kinds of rail steel: steel no. 1 is low in manganese $(0.05 \%$ $\mathrm{Mn})$ as compared to steel no. 2 . In this case the $\mathrm{Mn} / \mathrm{S}$ ratio equaled to 1.28 , and 32 in steel no. 2 .

The results of calculations of sulphur and manganese segregation real and equilibrium solubility manganese sulphide product for steel no. 1 at $\mathrm{MnS}$ activity equal to 0.6 and 1 were presented in the form of plots in figures 3 to 8 . During solidification the liquid phase is enriched with sulphur and manganese, and a consequence of this is a high content of components dissolved in the last portions of liquid steel. The analysis of the sulphur and manganese segregation line for steel no. 1 reveals that sulphur content in liquid steel with back diffusion would increase over 100 times, whereas at the MnS activity equal to 1 the sulphur final concentration in liquid steel would be higher than for MnS activity of 0.6. The course of the real and equilibrium product of solubility shows that at the casting rate of $100 \mathrm{~K} / \mathrm{min}$ the manganese sulphide is not formed either for MnS activity of $\mathrm{a}=0.6$ nor $\mathrm{a}=1$ (Fig. 4 and Fig. 6). It was observed that $\mathrm{MnS}$ precipitation $(\mathrm{a}=1)$ is formed at a casting rate of $500 \mathrm{~K} / \mathrm{min}$ (Fig. 8).

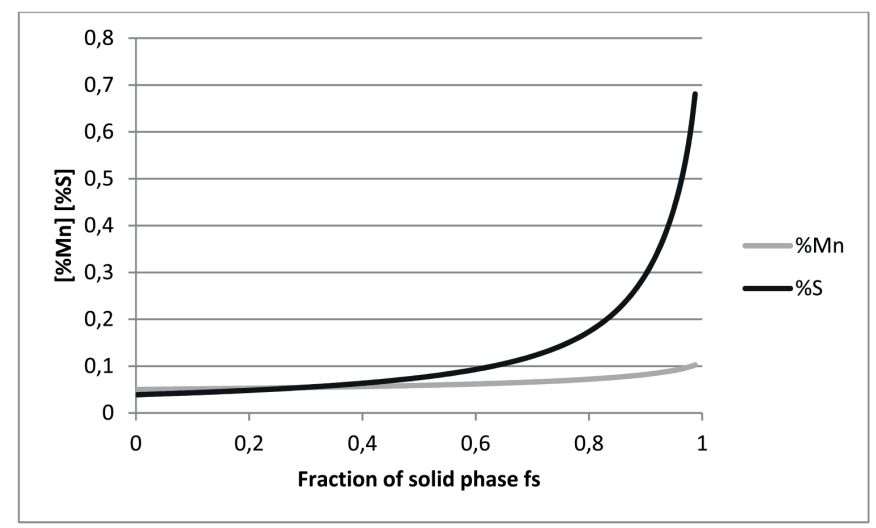

Fig. 3. Microsegregation of $\mathrm{Mn}$ and $\mathrm{S}$ during solidification of steel no. 1 at the cooling rate of $100 \mathrm{~K} / \mathrm{min}$ for steel no. 1 . MnS activity in precipitations equals to 1

Chemical composition of rail steel, wt. $\%$

\begin{tabular}{|c|c|c|c|c|c|c|c|c|c|c|}
\hline \hline $\mathbf{C}$ & $\mathbf{M n}$ & $\mathbf{S i}$ & $\mathbf{P}$ & $\mathbf{S}$ & $\mathbf{A l}$ & $\mathbf{V}$ & $\mathbf{C r}$ & $\mathbf{N i}$ & $\mathbf{M o}$ & $\mathbf{O}$ \\
\hline 0.054 & 0.05 & - & 0.007 & 0.039 & - & - & 0.05 & 0.03 & 0.06 & 0.001 \\
\hline 0.71 & 0.89 & 0.23 & 0.023 & 0.028 & 0.0056 & 0.005 & 0.05 & 0.03 & 0.005 & 0.001 \\
\hline
\end{tabular}




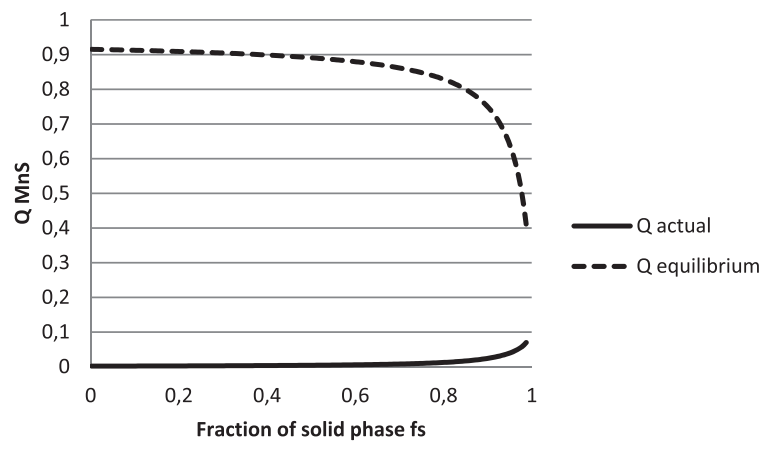

Fig. 4. Comparison of equilibrium and real solubility product at a cooling rate of $100 \mathrm{~K} / \mathrm{min}$ for $\mathrm{MnS}$. MnS activity in precipitations equals to 1

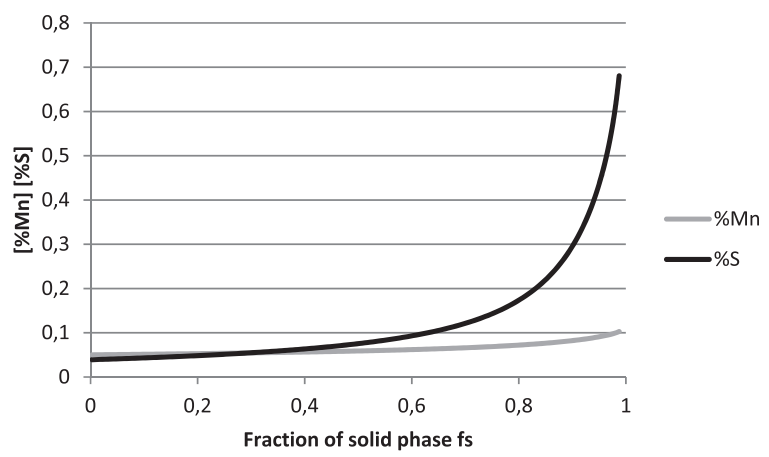

Fig. 5. Mn and $\mathrm{S}$ microsegregation during solidification of steel no. 1 at a cooling rate of $100 \mathrm{~K} / \mathrm{min}$ for steel no. $1 . \mathrm{MnS}$ activity in precipitations equals to 0.6

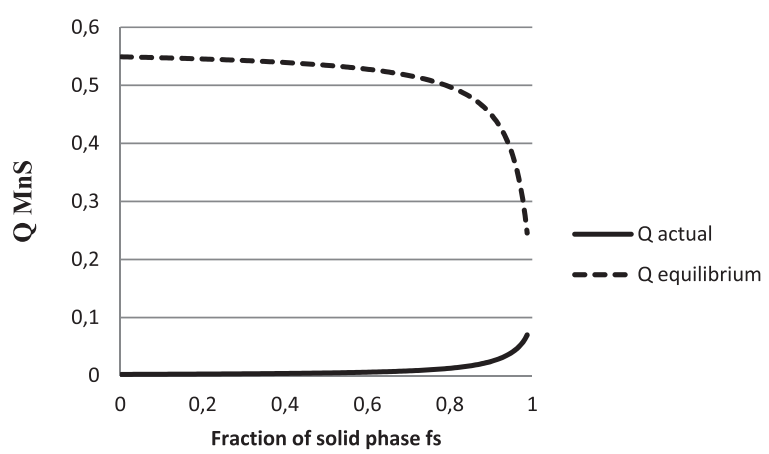

Fig. 6. Comparison of equilibrium and real solubility product at a cooling rate of $100 \mathrm{~K} / \mathrm{min}$ for $\mathrm{MnS}$. MnS activity in precipitations equals to 0.6

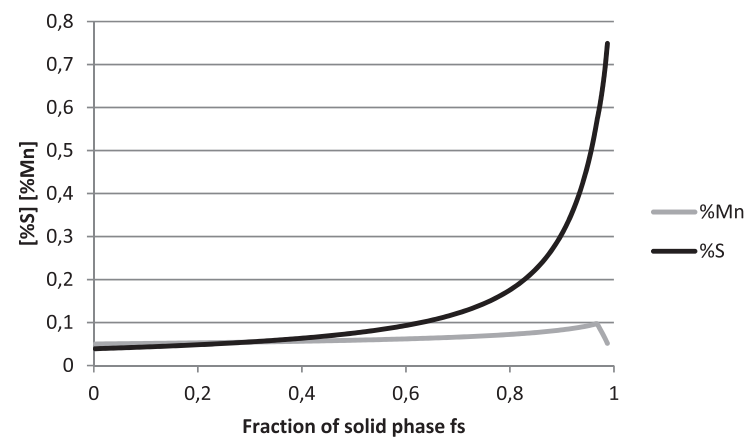

Fig. 7. Microsegregation of $\mathrm{Mn}$ and $\mathrm{S}$ during solidification of steel no. 1 at the cooling rate of $500 \mathrm{~K} / \mathrm{min}$ for steel no.1. MnS activity in precipitations equals to 1

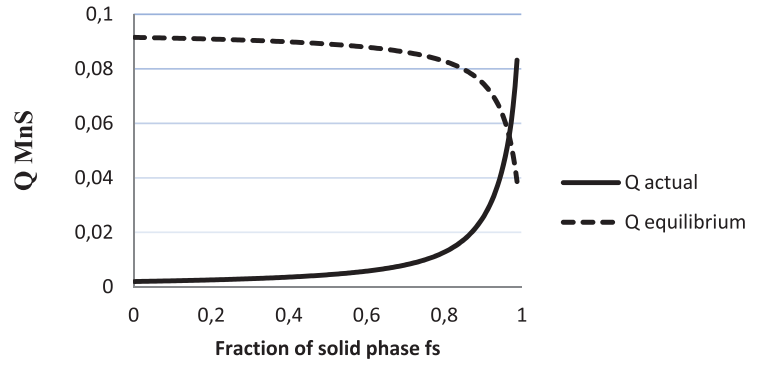

Fig. 8. Comparison of equilibrium and real solubility product at a cooling rate of $500 \mathrm{~K} / \mathrm{min}$ for $\mathrm{MnS}$. MnS activity in precipitations equals to 1

The sulphur and manganese segregation plots and the course of real and equilibrium solubility $\mathrm{MnS}$ product for solidification of steel no. 2 are presented in figures 9 to 12 . The $\mathrm{MnS}$ precipitation was observed at a casting rate of $100 \mathrm{~K} / \mathrm{min}$ both for pure sulphide $(\mathrm{a}=1)$ and a component of a solution $(\mathrm{a}=0.6)$. The main factor conditioning $\mathrm{MnS}$ formation in this steel is high Mn content. In this case the $\mathrm{MnS}$ inclusions are formed with the participation of solid phase of ca. 0.8 , while in steel no. 1 the sulphide phase is formed with the participation of about 0.97 of solid phase. It was also noted that the casting rate has an influence on the precipitation processes. In the case of steel no. 2 at the casting rate of $100 \mathrm{~K} /$ min the sulphide phase precipitates with the solid phase at a level of 0.77 for $\mathrm{a}=0.6$ and 0.825 for $\mathrm{a}=1$. The increased rate of casting to $500 \mathrm{~K} / \mathrm{min}$ causes that the precipitation process takes place at a higher participation of solid phase and the sulphide precipitation of activity 0.6 occurs earlier.

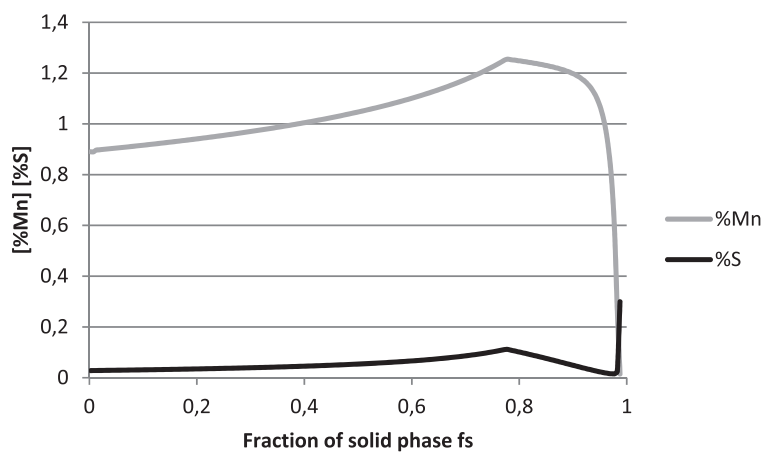

Fig. 9. Microsegregation of $\mathrm{Mn}$ and $\mathrm{S}$ during solidification of steel no. 2 at the cooling rate of $100 \mathrm{~K} / \mathrm{min}$ for steel no. 1 . MnS activity in precipitations equals to 0.6

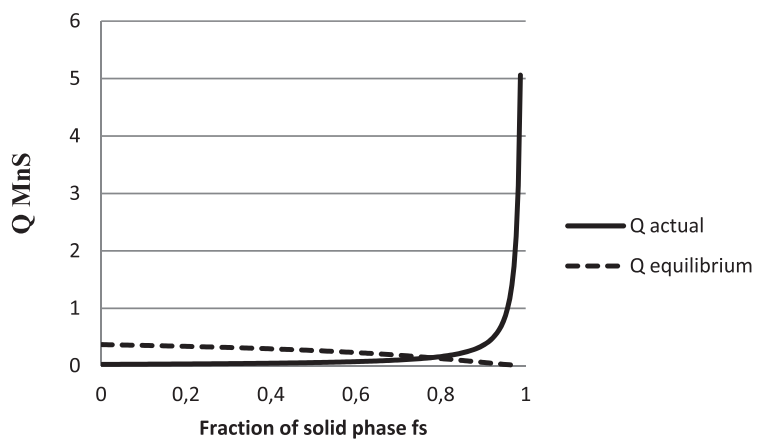

Fig. 10. Comparison of equilibrium and real solubility product at a cooling rate of $100 \mathrm{~K} / \mathrm{min}$ for $\mathrm{MnS}$. MnS activity in precipitations equals to 0.6 


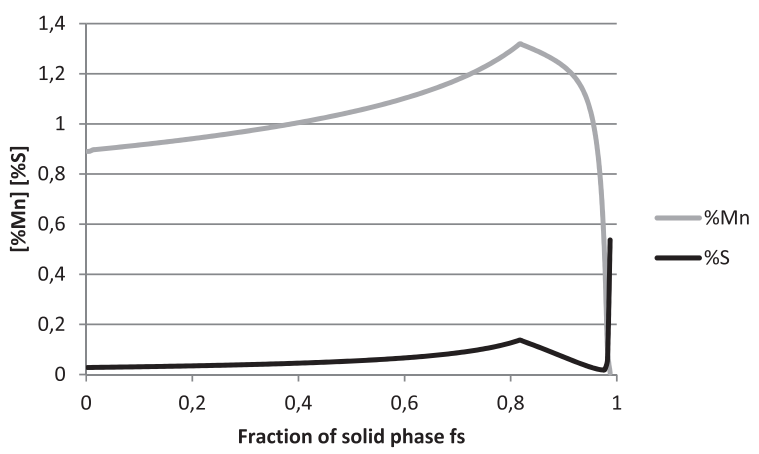

Fig. 11. Microsegregation of $\mathrm{Mn}$ and $\mathrm{S}$ during solidification of steel no. 2 at the cooling rate of $500 \mathrm{~K} / \mathrm{min}$ for steel no. 2 . MnS activity in precipitations equals to 0.6

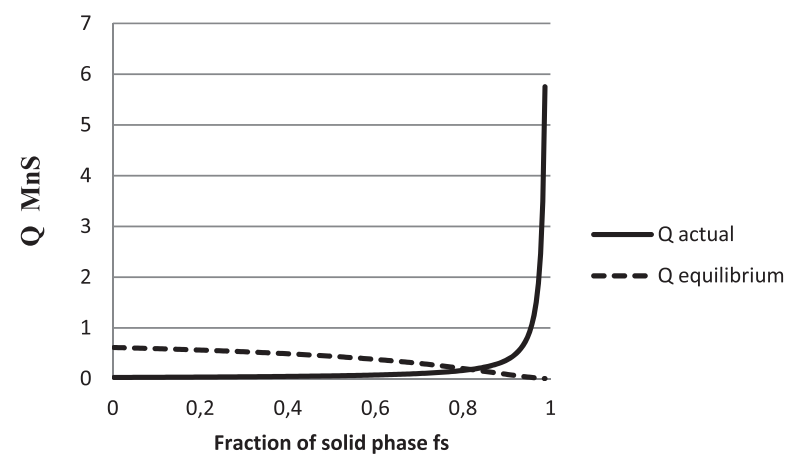

Fig. 12. Comparison of equilibrium and real solubility product at a cooling rate of $500 \mathrm{~K} / \mathrm{min}$ for $\mathrm{MnS}$. MnS activity in precipitations equals to 0.6

It follows from the results obtained from the simulation of the process of segregation and $\mathrm{MnS}$ inclusions formation that the precipitations generation is determined by the concentration of both components making up the inclusion. The moment of formation and quantity of $\mathrm{MnS}$ depends on the concentration of the component, whose deficiency is observed first. In this case this is manganese for steel no. 1 and sulphur for steel no. 2. Figures 7 and 9 illustrate the course of manganese and sulphur concentration; at both solidification rates the plots break showing to the formation of precipitations. The comparison of the sulphur and manganese segregation curves reveals a considerable difference lying in the fact that after sulphur concentration has been lowered by $\mathrm{MnS}$ formation, its concentration rapidly grows in the last portions of the solidifying liquid. This effect is caused by strong microsegregation of sulphur, stemming from the low value of equilibrium interfacial division, which equaled to 0.05 for sulphur.

\section{Analysis of the steel structure}

For the sake of identifying nonmetallic inclusions in rail steel the microstructure was analyzed with the use of Scanning Electron Microscopy (SEM). During experiments various types of precipitations were analyzed for their shape and chemical composition. Proper experiments were preceded by observations of the structure with an optical microscope. There was also performed point microanalysis of the precipitation with a microprobe and X-ray microanalyzer. Figures 13 to 16 depict the microstructure of steel no. 2, i.e. picture of the microstructure and result of X-ray microanalysis of the precipitation area. Elongated precipitations were noted to dominate; they were mainly composed of $\mathrm{Mn}$ and $\mathrm{S}$, identified as manganese sulphides. The elongated shape of the inclusions results from the plastic processing of steel and the direction of rolling. There are also fine irregular inclusions (fig. 15). The X-ray analysis of the inclusion area revealed that the object includes: $\mathrm{Mn}$, $\mathrm{S}$ and $\mathrm{O}$, therefore it can be postulated that the inclusion has a oxidix-sulphidic character (fig. 15). The inclusion was not deformed in the direction of rolling, which is also indicative of the fact that this inclusion was not purely sulphidic.

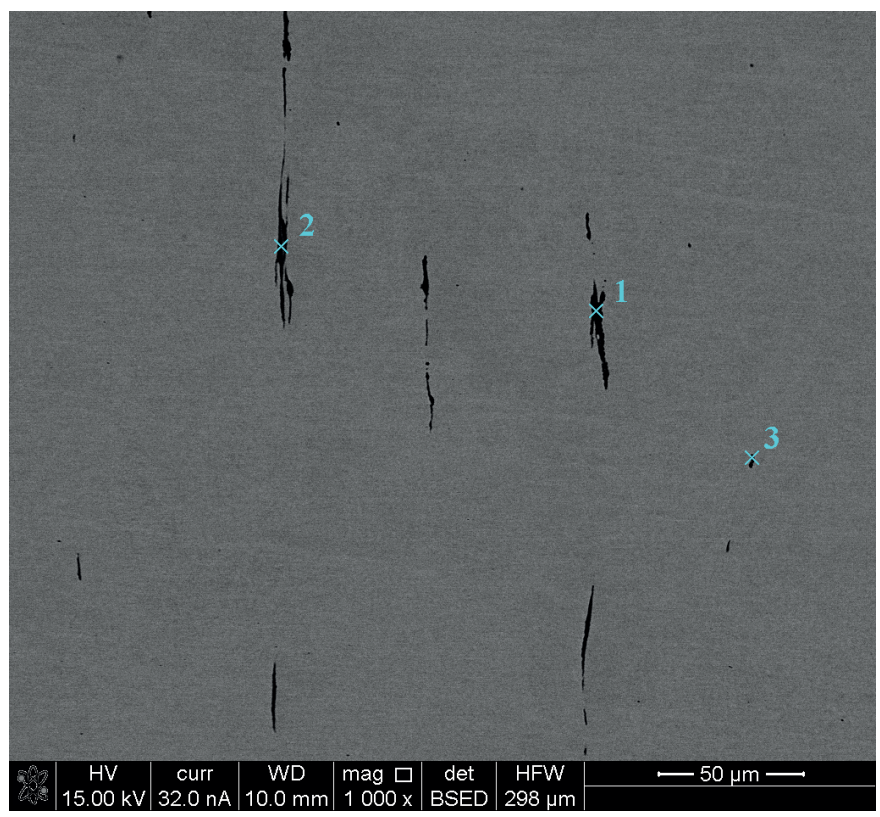

Fig. 13 Microstructure obtained with SEM

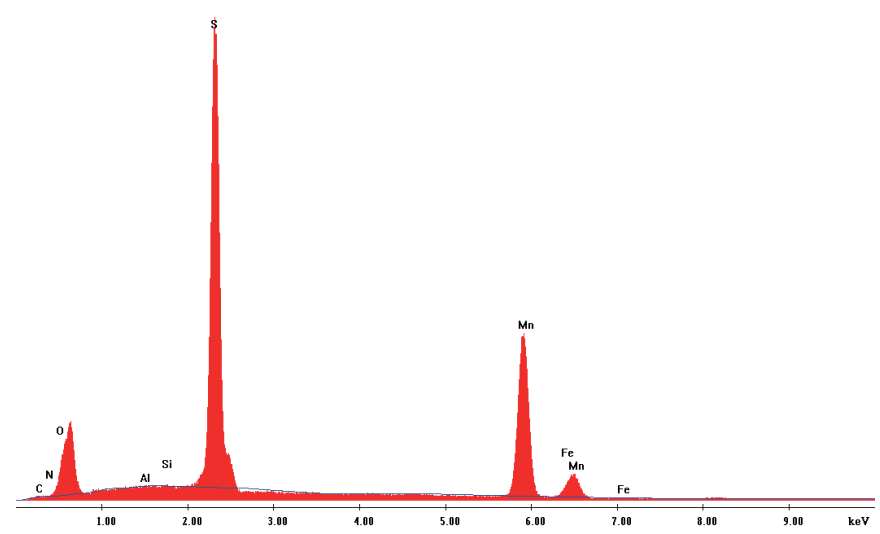

Fig. 14. Plot of point X-ray analysis obtained for point 1 of the inclusion marked in figure 13 


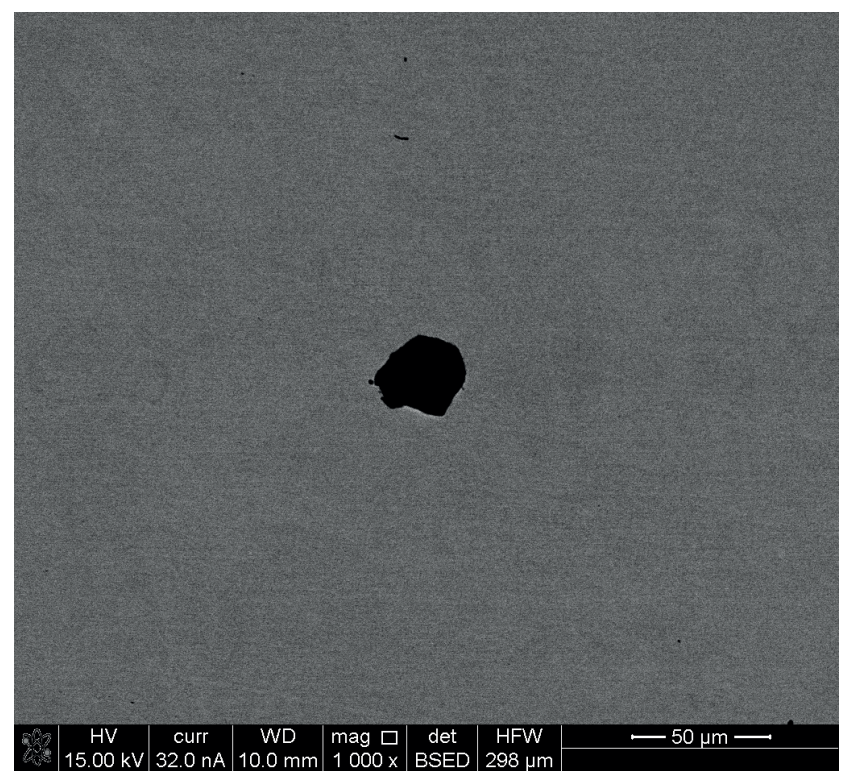

Fig. 15. Microstructure obtained in SEM (pt. 3 in fig. 13)

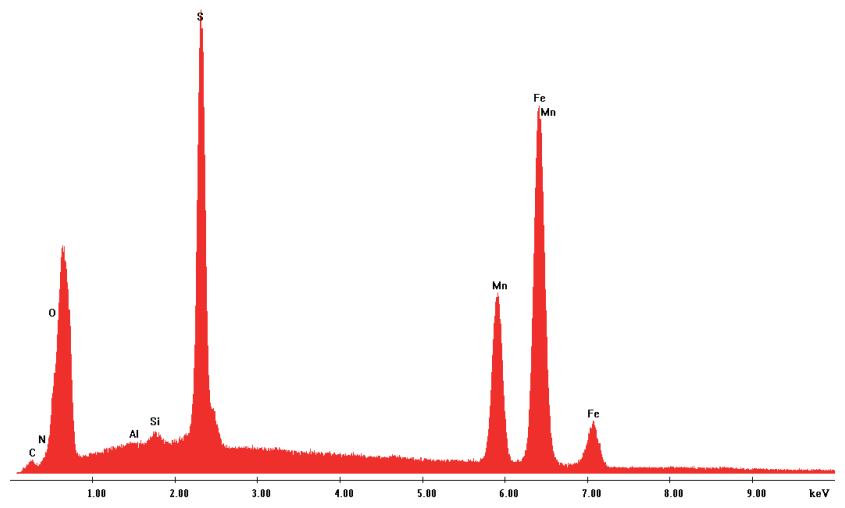

Fig. 16 Plot of point X-ray analysis obtained for point 1 of the inclusion

\section{Conclusions}

High metallurgical purity largely depends on the presence of oxidic nonmetallic inclusions, which get to the crystallizer during solidification, where they will play the role of heterogeneous nucleation centers for sulphides. The results of the simulation of $\mathrm{MnS}$ formation illustrate the fact that the inclusion formation is conditioned by the concentration of both components making up the inclusion. On the other hand, the amount of the formed compound depends on the concentration of the component, whose deficiency is observed first. These results do not give a full picture of the distribution of inclusions in the microstructure of the ingot, because the inclusions formed in the course of solidification do not have to be entrained by the moving crystallization front. The casting parameters also decide about the inclusions formation processes. The formation of secondary distribution of inclusions in the cast ingot is a complex process, therefore its modeling should also account for the kinetic factor.

\section{Acknowledgement:}

This study was solved within the framework of the project Reg. No. 11. 11.170.318.14

at financial support of Ministry of Science and Higher Education Republic of Poland.

\section{REFERENCES}

[1] C.D. Liu, M. N. Bassim, S. Stlawrence, Structural Materials Properties Microstructure and Processing 167, 107-113 (1993).

[2] T. Miyake, M. Morishita, H. Nakata, M. Kokita, ISIJ Int. 46, 1817 - 1822 (2006).

[3] J. Hucińska, Advances in Materials Science 16-25 (2006).

[4] Subvolume E 'Dy-Er - Fr-Mo' of Volume 5 'Phase Equilibria, Crystallographic and Thermodynamic Data of Binary Alloys' of Landolt-Börnstein - Group IVPhysical Chemistry.

[5] D. Kalisz, S. Rzadkosz, Archives of Foundry Engineering 13, 1, 63-68 (2013).

[6] D. Kalisz, P. L. Żak, J. Lelito, M. Szucki, J. S. Suchy, B. Gracz, Metallurgy 54, 1, 139-142 (2015).

[7] D. Kalisz, The Thermodynamic Characteristic of the Non - Metallic Phase Formation in the Liquid Steel, Scientific Publishing Company Akapit, AGH-UST, Krakow 2013.

[8] Z. Liu, K. Gu, K. Cai, ISIJ Int., 42, 950 - 957 (2002).

[9] W. Wołczyński, Effect of the Back-Diffusion onto Doublet Structure Formation and Solute Redistribution within Alloys Solidyfying Directionally, with or without Convection, Polish Academy of Sciences, Institute of Metallurgy and Materials Science, Krakow 2002.

[10] Z. Morita, T. Tanaka, T. Yanai, Met. Trans. B 18B, 195-202 (1987).

[11] Z. Ma, D. Janke, ISIJ Int. 38, 46-52 (1998).

[12] Z. Liu, J. Wei, K. Cai, ISIJ Int. 42, 958 - 963 (2002).

[13] S. Kobayashi, T. Nagamichi, K. Gunji, ISIJ Int. 28, 543 - 552 (1988).

[14] T. Matsumiya, H.Kajioka, S. Mizoguchi, Y. Ueshima, H. Esaka, ISIJ Int. 24, 873 - 882 (1984).

[15] J. Wypartowicz, D. Podorska, Hutnik 71, (6) 259 - 264 (2004).

[16] K. Płaczek, D. Podorska, J. Wypartowicz, Ciągłe Odlewanie Stali, Krynica 16-18.06, 265-274 (2004).

[17] H. Goto, K. Miyazawa, W. Yamada, K. Tanaka, ISIJ Int. 35, $708-714$ (1995).

[18] M. Suzuki, R. Yamaguchi, K. Murakami, M. Nakada, ISIJ Int. 41, $247-256$ (2001).

[19] P. L. Zak, D. Kalisz, J. Lelito, M. Szucki, B. Gracz, J.S. Suchy, Metalurgija 54, 357-360 (2015).

[20] J. Iwanciw, D. Podorska, J. Wypartowicz, Archives of Metallurgy and Materials 52, 999-1005 (2011).

[21] D. Podorska, D. Drożdż, J. Falkus, J. Wypartowicz, Archives of Metallurgy and Materials 51, 581-586 (2006).

[22] J. Iwanciw, D. Podorska, J. Wypartowicz, Archives of Metallurgy and Materials 56, 635-644 (2011).

[23] D. Kalisz, P. L. Żak, Kovove Mater. 53, 1, 35-41 (2015).

[24] J. S. Suchy, J. Lelito, B. Gracz, P. L. Żak, China Foundry 9 , (2), 184-188 (2012). 